\title{
Histological findings in women with postmenopausal bleeding: Jordanian figures
}

\author{
I. Bani-Irshaid ${ }^{7}$ and A. Al-Sumadi ${ }^{7}$
}

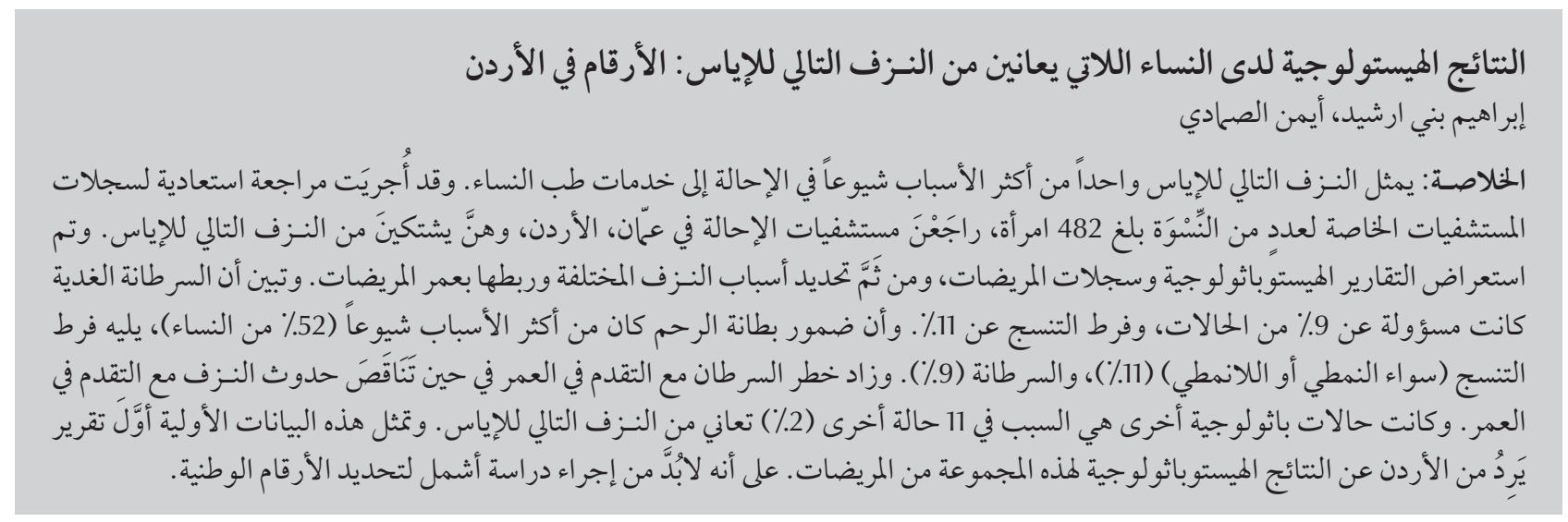

ABSTRACT Postmenopausal bleeding represents one of the most common reasons for referral to gynaecological services. A retrospective review was made of the hospital records of 482 women presenting with postmenopausal bleeding to a referral hospital in Amman, Jordan. Histopathological reports and patients' records were reviewed and different causes of bleeding were identified and related to patients' age. Adenocarcinoma was responsible for $9 \%$ of cases, and hyperplasia for $11 \%$. Atrophy of the endometrium was the most common finding (52\% of women), followed by hyperplasia (with and without atypia) (11\%) and carcinoma (9\%). The risk of cancer increased with increasing age while the incidence of bleeding decreased with age. Other pathology was reported as the main finding in 11 cases (2\%) with postmenopausal bleeding. These preliminary data are the first reports from Jordan of histopathological findings in this group of patients, and a larger study is required to establish national figures.

Résultats histologiques chez des femmes ménopausées présentant des saignements gynécologiques : données jordaniennes

RÉSUMÉ Les saignements chez les femmes ménopausées représentent l'un des motifs les plus fréquents d'orientation vers les services gynécologiques. Les dossiers médicaux de 482 femmes ménopausées admises dans un hôpital de recours à Amman (Jordanie) pour des saignements gynécologiques ont fait l'objet d'une étude rétrospective. Les comptes rendus histopathologiques et les dossiers médicaux ont été étudiés et différentes causes de saignement ont été identifiées et reliées à l'âge des patientes. Un adénocarcinome était à l'origine de $9 \%$ des cas, et une hyperplasie de $11 \%$ des cas. Le résultat le plus fréquent était une atrophie de l'endomètre (52\% des femmes), suivi par une hyperplasie (atypique ou non, $11 \%$ ) et un carcinome (9\%). Le risque de cancer augmentait parallèlement à l'âge alors que l'incidence des saignements diminuait avec l'âge. Chez onze femmes ménopausées (2\%), les saignements gynécologiques étaient provoqués par une autre pathologie. Ces données préliminaires représentent le premier rapport jordanien sur les résultats histopathologiques dans ce groupe de patientes, et une étude à plus grande échelle est requise pour rassembler des données nationales. 


\section{Introduction}

Postmenopausal bleeding represents one of the most common reasons for referral to gynaecological services, largely due to suspicion of an underlying endometrial malignancy [1]. A woman not taking hormone replacement therapy (HRT) who bleeds after the menopause has a 10\% risk of having genital cancer and a further 10\% risk of significant pathology [2]. Therefore, postmenopausal bleeding should always be investigated no matter how minimal or nonpersistent. Causes may be nongenital, genital, uterine or extrauterine. Traumatic bleeding from an atrophic vagina may account for up to $15 \%$ of all causes of postmenopausal bleeding [3]. Endometrial atrophy is the most common endometrial finding in women with postmenopausal bleeding, accounting for $60 \%-80 \%$ of such bleeding [4]. Unrecognized and untreated polyps may be a source of continued or recurrent bleeding, leading eventually to unnecessary hysterectomy $[4,5]$.

Endometrial hyperplasia occurs in $5 \%-10 \%$ of patients with postmenopausal uterine bleeding [6]. Oestrogen is an established risk factor for endometrial hyperplasia and cancer. The source of excess oestrogen should be considered, including obesity, exogenous oestrogen or an oestrogenic-secreting ovarian tumour [7]. Clinically significant hyperplasia usually evolves within a background of proliferative endometrium as a result of protracted oestrogen stimulation in the absence of progesterone influence [8]. Not only is endometrial hyperplasia important because of the possibility of abnormal uterine bleeding but it may also precede or occur simultaneously with endometrial cancer $[9,10]$. Postmenopausal bleeding is the most common presenting symptom in women diagnosed with endometrial cancer $[11,12]$.

A number of studies on endometrial histopathology in postmenopausal women have been conducted worldwide, but there are few in the Eastern Mediterranean Region and none in Jordan to determine the size of the problem and the risks in our population. One study in Israel was conducted on the incidence of benign pathology, atrophic endometrium and risk of malignancy [13]. Although the ideal study will be population-based, we aimed in this study to present a hospital-based survey, hoping that we can present more informative results from populationbased data in the future.

\section{Methods}

The study was a retrospective review of records over a 4-year period between May 1998 and May 2002 in King Hussein Medical Centre, a referral hospital accepting referrals from 5 different hospitals in Jordan: Prince Rashed Hospital (Irbid, north Jordan); Prince Hashem Hospital,Zarqa (eastJordan); Prince Ali Hospital (Karak, south Jordan); Prince Zaid Hospital (Tafelah, south Jordan); and Princess Rashed Hospital (Aqaba, south Jordan). The women of the sample were therefore fairly representative of the whole population of Jordan presenting to gynaecology departments with postmenopausal bleeding.

We reviewed the records of all women who presented to King Hussein Medical Centre with postmenopausal bleeding over the study period. The inclusion criteria were referral to the gynaecology department of one of the Royal Medical Services hospitals because of uterine bleeding, appearing 1 year or more after menopause. Menstrual status, obstetric and medical history, as well as pharmacological therapy were reviewed. The results of gynaecological examinations were obtained from the medical records. Women taking HRT for vasomotor symptoms were excluded from the study. All women underwent $\mathrm{D} \& \mathrm{C}$, which was the routine treatment for these patients at King Hussein Medical Centre at that time. The histopathology reports were from 4 different pathologists and the final pathological diagnoses were taken verbatim from the reports. As this study was retrospective, we were unable to discuss the reports with the pathologist or reanalyse them.

A total of 482 reports were reviewed: 14 were excluded because the women were taking HRT, and the remaining 468 reports were analysed. The endometrial specimens were divided into the following histological categories: atrophy; proliferation; secretion; endometrial poly; simple or cystic hyperplasia; adenomatous hyperplasia; atypical hyperplasia; carcinoma; other, including sample not representative, samples with only fibromuscular tissue and samples too scanty for appropriate evaluation.

\section{Results}

The mean age of women with postmenopausal bleeding was 55.3 years (range 41-85 years) and the median age when menopause occurred was 50.6 years. Figure 1 shows the frequency of bleeding of different age groups. The incidence of postmenopausal bleeding declined with increasing age.

The histopathological findings in the endometrium of women with postmenopausal bleeding are shown in Table 1. Atrophy of the endometrium was the most common finding ( $52 \%$ of women), followed by hyperplasia (with and without atypia) (11\%) and carcinoma (9\%).

Figure 2 illustrates the rate of endometrial cancer as the underlying cause in different age groups in our population. The rate was highest in the age group 70-74 years.

In women younger than 60 years of age, $8.7 \%$ of the specimens were classified as "not representative" and the corresponding figure for women older than 60 years was $18.8 \%$. 


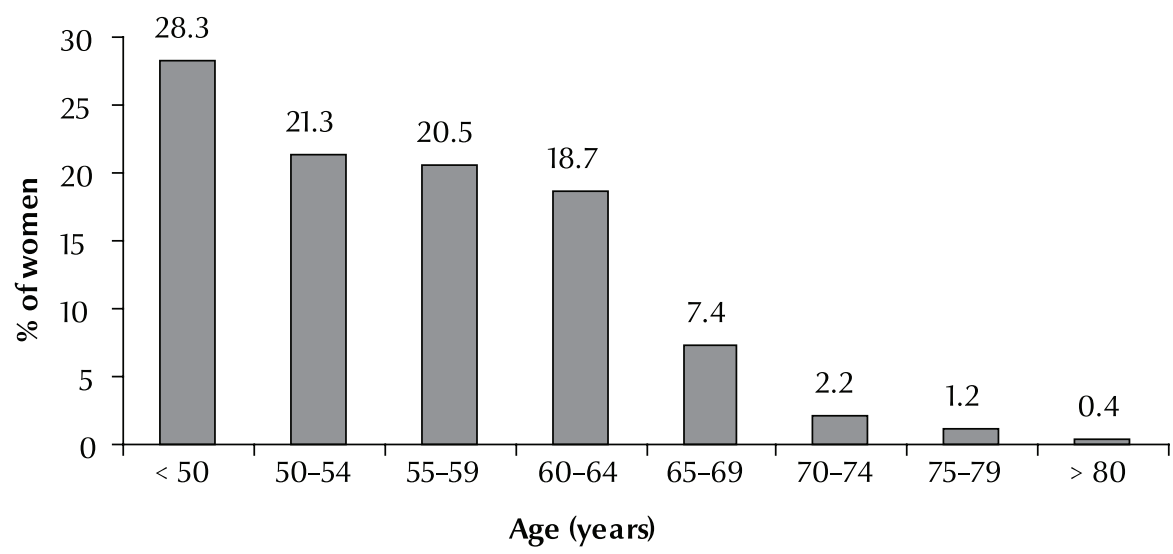

Figure 1 Age of women with postmenopausal bleeding $(n=468)$

Of the 11 women classified with extrauterine pathology "other disorders", 3 (0.6\%) had cervical squamous carcinoma and 8 (1.7\%) had ovarian tumours ( 3 mutinous borderline tumours; 2 mature cystic teratoma and 3 thecomas, of which 2 were combined with adenomatous hyperplasia).

\section{Discussion}

Few analyses of the causes of uterine bleeding in postmenopausal women are based on representative populations. This study included all women presenting with uterine bleeding after the menopause in a defined health care region during a period of 4 years.

Although the diagnostic accuracy of $\mathrm{D} \& \mathrm{C}$ is still controversial, it was used in this study since, until recently, it was the investigation of choice at Royal Medical Services hospitals. Since early 2004, hysteroscopic-guided biopsy has been introduced to the hospitals. A high percentage of the specimens obtained in this study (13\%), most of which were obtained from women older than 60 years, were not representative of the endometrium and were inadequate for evaluation. Different studies showed different figures of sample impossible to evaluate because they were inadequate (10\%-20\%) [13-15].

In our study atrophy of the endometrium was the predominant finding in the women in the postmenopausal period (52\%), a figure which is comparable to that of a regional study in Israel (42.8\%) [13]. It is not known why some patients tend to bleed from an atrophic endometrium. Anatomical vascular variations or local abnormal

\begin{tabular}{lcc}
\hline Table 1 Histopathological findings among women with postmenopausal bleeding \\
\hline Endometrial appearance & No. & $\%(\boldsymbol{n}=\mathbf{4 6 8})$ \\
Atrophy & 243 & 51.9 \\
Proliferation & 19 & 4.1 \\
Secretion & 16 & 3.4 \\
Polyps & 24 & 5.1 \\
Hyperplasia, with and without atypia & 52 & 11.1 \\
Carcinoma & 43 & 9.2 \\
Not representative & 60 & 12.8 \\
Other disorders & 11 & 2.4 \\
\hline
\end{tabular}

haemostatic mechanisms in the uterus have been proposed as the mechanism $[14,15]$

Adenocarcinoma of the endometrium was found in $9 \%$ of the samples. The incidence of endometrial carcinoma in studies published between 1985 and 2004 varied between 3.7\% and 17.9\% $[10,12,16-18]$; many of these reports focused on malignancy and, like our study, were based only on hospitalized women. Although the rate of postmenopausal bleeding declined with increasing age, the peak incidence of endometrial carcinoma occurred in the age group $70-74$ years $[15,16]$. An increasing incidence of uterine malignancy in women with age has been demonstrated before $[19,20]$.

Adenomatous hyperplasia, with or without atypia, is considered to be a precursor of carcinoma [13] and was found in about $11 \%$ of women in the present study. The relatively low incidence of hyperplasia as the cause of bleeding could be due both to the strict selection of postmenopausal women and to the fact that none had been treated with oestrogen replacement therapy. The incidence of benign endometrial polyps (5\%) was lower than previous findings by Lidor et al. [4] and Gredmark et al. [15]. In our study $3 \%$ of the postmenopausal women had an endometrium 


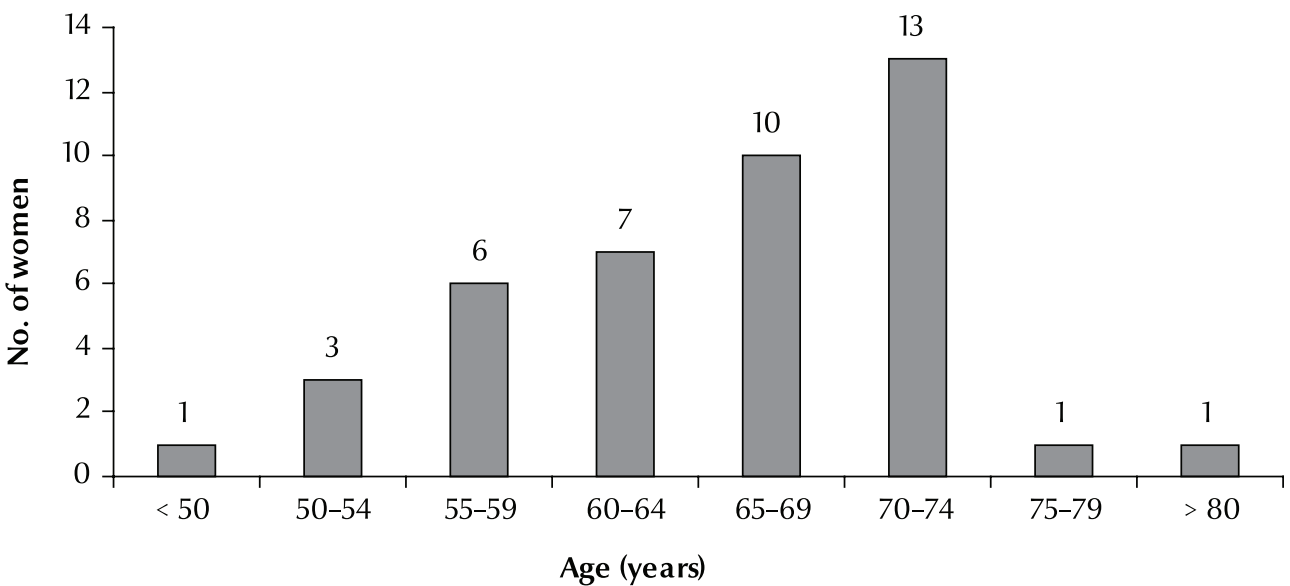

Figure 2 Number of cases of endometrial cancer in different age groups $(n=42)$

characterized as secretory. This could be due to fluctuating levels of progesterone from follicular remnants, as the decline of ovarian function in postmenopausal women is a gradual process.

Carcinoma of the cervix was found in only 3 women $(0.6 \%)$. This was lower that the study in Israel $(2.5 \%, 11$ out of 398) [13] and contrasts with a report from European countries describing malignant conditions in $30 \%$ of women presenting with postmenopausal bleeding, almost one-third of which were cervical squamous cell carcinomas [17]. Our figure also needs to be interpreted in the absence of a cervical screening programme in our country, as cervical cancer risk declines when effective screening programmes are in place. The low incidence of cervical cancer is in agreement with other figures from conservative societies $[12,13]$.

In 8 women significant ovarian pathological conditions were observed. These observations support the use of transvaginal scan ultrasound in the evaluation of postmenopausal bleeding, especially since endometrial carcinoma has been found to be extremely rare in women with an endometrial thickness less than $5 \mathrm{~mm}$ [21].

In conclusion, this retrospective study of postmenopausal women with uterine bleeding showed that the number of women with bleeding decreased with increasing age, while the probability of endometrial cancer as the underlying cause increased. It is important to note that about $50 \%$ of the women with postmenopausal bleeding had an atrophic endometrium, which is similar to other parts of the world including this region (Saudi Arabia, Israel). Due to the prevalence of low endometrial thickness found in our sample of postmenopausal women they are not at high risk of endometrial cancer. These preliminary data are the first reports from Jordan of histopathological findings in this group of patients, and a larger study is required to establish national figures. It is proposed that postmenopausal bleeding can be managed expectantly in patients for whom an ultrasound examination demonstrates ordinary adnexa and a thin endometrial mucosa.

\section{References}

1. Hawwa ZM, Nahhas WA, Copenhaver EH. Postmenopausal bleeding. Lahey Clinic Foundation Bulletin, 1970, 19:61-70.

2. Astrup K, Olivarius NDeF. Frequency of spontaneously occurring postmenopausal bleeding in the general population. Acta Obstetricia et Gynecologica Scandinavica, 2004, 83(2):203-7.

3. Pacheco JC, Kempers RD. Etiology of postmenopausal bleeding. Obstetrics and Gynecology, 1968, 32:40-46.

4. Lidor A et al. Histopathological findings in 226 women with postmenopausal bleeding. Acta Obstetricia et Gynecologica Scandinavica, 1986, 65:41-43.

5. Parazzini F et al. The epidemiology of endometrial cancer. Gynecologic Oncology, 1991, 41:1-16.

6. Norris HJ, Tavassoli FA, Kurman RJ. Endometrial hyperplasia and carcinoma. Diagnostic considerations. American Journal of Surgical Pathology, 1983, 7(8):839-847.
7. Alberico S et al. A clinical and epidemiological study of 245 postmenopausal metrorrhagia patients. Clinical and Experimental Obstetrics and Gynecology, 1989, 16:113-121.

8. Gordon MD, Ireland K. Pathology of hyperplasia and carcinoma of the endometrium. Seminars in Oncology, 1994, 21(1):64-70.

9. Hunter JE et al. The prognostic and therapeutic implications of cytologic atypia in patients with endometrial hyperplasia. Gynecologic Oncology, 1994, 55:66-71.

10. Escoffery CT, Blake GO, Sargeant LA. Histopathological findings in women with postmenopausal bleeding in Jamaica. West Indian Medical Journal, 2002, 51(4):232-235.

11. Goff BA et al. Uterine papillary serous carcinoma: patterns of metastatic spread. Gynecologic Oncology, 1994, 54:264-268. 
12. Al-Kadri HM, Al-Awami SH, Madkhali AM. Assessment of risk factors of uterine cancer in Saudi patients with postmenopausal bleeding. Saudi Medical Journal, 2004, 25(7):857-861.

13. Caspi E, Perpinial S, Reif A. Incidence of malignancy in Jewish women with postmenopausal bleeding. Israel Journal of Medical Sciences, 1977, 13(3):299-304.

14. Fortier KJ. Postmenopausal bleeding and the endometrium. Clinical Obstetrics and Gynecology, 1986, 29:44-45.

15. Gredmark T, Havel G, Mattsson L-A. Histopathological findings in women with postmenopausal bleeding. British Journal of Obstetrics and Gynaecology, 1995, 102(2):133-136.

16. Kuwashima $\mathrm{Y}$ et al. Intramural carcinomas of the uterine corpus: a clinicopathological study. In Vivo, 1997, 11(3):253-260.

17. Ross JC et al. Primary mucinous adenocarcinoma. Seminars in Oncology, 1994, 21:64-70.
18. Sherman ME et al. Uterine serous carcinoma. A morphologically diverse neoplasm with unifying clinicopathologic features. American Journal of Surgical Pathology, 1992, 16:600610.

19. Hendrickson MR, Ross JC, Kempson RL. Towards the development of morphologic criteria for well differentiated adenocarcinoma of the endometrium. American Journal of Surgical Pathology, 1983, 7:819-838.

20. Abeler VM, Kjorstad KE. Endometrial squamous cell carcinoma: report of three cases and review of the literature. Gynecologic Oncology, 1990, 36:321-326.

21. AbelerVM, Kjorstad KE. Clear cell carcinoma of the endometrium: a histopathological finding and clinical study of 97 cases. Gynecologic Oncology, 1991, 40:207-217.

\section{Women, ageing and health: a framework for action}

Women, ageing and health: a framework for action presents the evidence about women, ageing and health from a gender perspective and provides a framework for developing action plans to improve the health and well-being of ageing women. It serves as a complement to a longer publication entitled Women, ageing and health: a review. focus on gender. This report endeavours to provide information on ageing women in both developing and developed countries; however, data are often scant in many areas of the developing world.

Some implications and directions for policy and practice based on the evidence and known best practices are included in the report. These are intended to stimulate discussion and lead to specific recommendations and action plans. The report provides an overall framework for taking action that is useful in all settings.

Further information about this and other WHO publications is available at: http://www.who.int/publications/en/ 